\title{
Factors affecting morbidity and mortality in traumatic colorectal injuries and reliability and validity of trauma scoring systems
}

\author{
Nurettin $A y^{1 *}$, Vahhaç Alp ${ }^{2}$, Ibrahim Aliosmanoğlư ${ }^{3}$ Utkan Sevük ${ }^{4}$, Şafak Kaya ${ }^{5}$ and Bülent Dinç ${ }^{6}$
}

\begin{abstract}
Background and aim: This study aims to determine the factors that affect morbidity and mortality in colon and rectum injuries related with trauma, the use of trauma scoring systems in predicting mortality and morbidity.

Patients and methods: Besides patient demographic characteristics, the mechanism of injury, the time between injury and surgery, accompanying body injuries, admittance Glasgow coma scale (GCS), findings at surgery and treatment methods were also recorded. With the obtained data, the abbreviated injury scale (AIS), injury severity score (ISS), revised trauma score (RTS) and trauma-ISS (TRISS) scores of each patient were calculated by using the 2008 revised AIS.

Results: Of the patients, 172 (88.7\%) were male, 22 (11.3\%) were female and the mean age was $29.15 \pm 12.392$ (15-89) years. The morbidity of our patients were $32 \%$ and mortality were $12.4 \%$. ISS $(p<0.001)$, RTS $(p<0.001)$, and the TRISS $(p<0.001)$ on mortality were found to be significant. TRISS $(p=0.008)$, the ISS $(p<0.001)$, the RTS $(p=0.03)$, the trauma surgery interval (TSI, $p<0.001$ ) were observed to have significant effects on morbidity.

Regression analysis showed that the ISS (OR 1.1; Cl $95 \%$ 1.01-1.2; $p=0.02)$, the RTS (OR 0.37; Cl $95 \% 0.21-0.67 ; p=0.001)$ had significant effects on mortality. While the effects of TSI (OR 5.3; CI $95 \%$ 1.5-18.8; $p=0.01$ ) on morbidity were found to be significant.

Conclusion: Predicting mortality by using scoring systems and close postoperative follow up of patients in the risk group may ensure decreases in the rates of morbidity and mortality.
\end{abstract}

Keywords: Trauma, Colorectal, TRISS, RTS, ISS

\section{Introduction}

Colorectal injuries are rare in trauma patients and are associated with increased mortality. These injuries constitute $1 \%$ of all trauma patients [1]. Most colonic and rectal injuries occur following penetrating trauma and injury from blunt trauma is uncommon [2]. The mortality associated with colonic trauma has decreased considerably over the last half century; from $40 \%$ during World War II to 1$3 \%$ over the last several decades [3]. Common postoperative complications include systemic complications such as pneumonia, sepsis and complications specific to

\footnotetext{
* Correspondence: nurettinay77@hotmail.com

'Diyarbakır Gazi Yaşargil Education and Research Hospital, Transplantation Center, Diyarbakır, Turkey

Full list of author information is available at the end of the article
}

abdominal surgery such as surgical site infection, intraabdominal abscess, and abdominal sepsis [4].

Staging according to the severity of injury is necessary for the management of trauma and as well as a basic requirement for clinical trials [5]. Trauma scoring systems try to translate the severity of injury into a number. The scores enable physicians to translate different severity of injuries into a common language [6]. Quantitative characterizations of injury are essential for research and meaningful evaluation of patient outcome, quality improvement, and prevention programs [6, 7]. For this purpose, many anatomical and physiological scoring systems are created [8]. There are around 50 scoring systems published for the classification of trauma patients [6]. Some of these scoring systems are new injury severity score (NISS), AIS, ISS, GCS, RTS and TRISS [9]. This study aims to determine the 
factors that affect morbidity and mortality in colon and rectum injuries related to trauma, to utilize trauma scoring systems for predicting mortality and morbidity.

\section{Materials and methods}

Between January 2005 and December 2010, all the patients who were operated on for blunt or penetrating abdominal injury at Dicle University Faculty of Medicine Hospital were evaluated retrospectively. One ninety four patients with colorectal injury were included in the study.

After the initial evaluation of the patients in the emergency room, a nasogastric catheter, a central venous pressure catheter and a foley catheter was placed into the patients. All the patients were given fluidelectrolyte resuscitation. In the preoperative period, the patients were simultaneously administered two antibiotics (intravenous ceftriaxone $1 g$ and metronidazole $500 \mathrm{mg}$ ). Antibiotic therapy was continued in the postoperative period and was stopped on the fifth day. Hemodynamically unstable patients were operated on under emergency conditions. Patients who were hemodynamically stable were assessed by physical examination, laboratory tests and imaging methods (radiography, ultrasonography, computed tomography), peritoneal lavage before proceeding with the surgery. One of these procedures for patients who were scheduled for surgery were performed primary repair+proximal diverting stoma (PDS), resection+anastomosis, primary closure or resection of injured bowel+PDS. Distal washout and presacral drainage were not performed for rectal injuries. Midline laparotomy was performed all patients.

Besides the demographic characteristics of the patients such as age and gender; the mechanism of the injury, the time between injury and surgery, accompanying body injuries (head and neck, face, chest, abdomen, extremities and external structures), vital signs at emergency admittance, GCS at admission, findings during the performed surgery and the treatment methods were also recorded. Follow up data after surgery, observed complications and the duration of time until discharge were evaluated. Trauma and/or operation related complications were defined as morbidity and deaths due to trauma and/or operation were defined as mortality.

With the obtained data, the AIS scores of each patient were calculated by using the 2008 revised AIS (AIS was calculated according to update 2008 dictionary in the www.aaam.org website). The ISS scores were calculated for each patient with the data from the three regions (regions: head \& neck, face, chest, abdomen, extremity, external) with the highest scores The RTS were calculated for each patient by using the findings of respiratory rate at admittance to the emergency room, systolic blood pressure and GCS data. The TRISS were calculated for each patient by using the patient ISS, RTS, age and trauma mechanism data. In order to calculate the ISS, RTS and the TRISS, the calculation tool available on the web site www.trauma.org were used.

All colonic injuries were divided into two categories as non-destructive (Flint scale grade 1-2) and destructive (Flint scale grade 3). The patients were divided into two groups, blunt injury group (BIG) and penetrating injury group (PIG), and a comparison was made between these two forms of trauma. The present study was approved by the Dicle University ethics committee and complies with the requirements of the Declaration of Helsinki.

\section{Statistical analysis}

Statistical analysis was performed by using the SPSS for Windows 11.5 (SPSS Inc. Chicago, IL, USA) program. Descriptive statistics were used for the evaluation of the data. The Kolmogorov-Smirnov test was used to determine the distribution of the data. The Chi-square test was used for the comparison of qualitative data between groups and the Mann-Whitney $U$ test was used for the comparison of quantitative data. The data were evaluated in terms of mean standard deviation. The regression test was used to determine the factors effecting morbidity and mortality. A $p$ value $<0.05$ was accepted as being statistically significant.

\section{Results}

Between January 2005 and December 2010, 3857 trauma patients were followed and treated by the general surgery department and the incidence of colorectal injury was detected to be $4 \%$. Colorectal injuries due to blunt trauma comprised $7.7 \%$ of all colorectal injuries. The common causes of injury were gunshot wound $(n=128$, $66 \%)$, cuts and puncture wounds $(n=51,26.3 \%)$, traffic accidents $(n=12,6.2 \%)$ and falls from a height $(n=3$, $1.5 \%)$. The majority of the patients with colorectal injuries had Flint grade 1 injuries (53.1\%). Sixty two percent of the cases were managed by primary closure. The morbidity of the patients were $32 \%$ and mortality was $12.4 \%$. The descriptive data of the study is presented in Figs. 1, 2 and 3.

A hundred and fifty one (77.8\%) patients had accompanying additional organ injuries. Fifty-eight $(29.9 \%)$ patients had two or more additional organ injuries. The most common organ injuries seen with colon injuries were small bowel injuries (Table 1).

Comparison of characteristics of BIG and PIG are presented in Table 2. When compared to the PIG, the rates of morbidity $(p=0.02)$, mortality $(p=0.02)$ and the rates of patients treated after 8 hours $(p=0.008)$ of the injury in the BIG were significantly higher. In the BIG, the mean RTS was significantly lower than in the PIG $(p=0.037)$ (Table 2). 


\section{Flint injury scale}

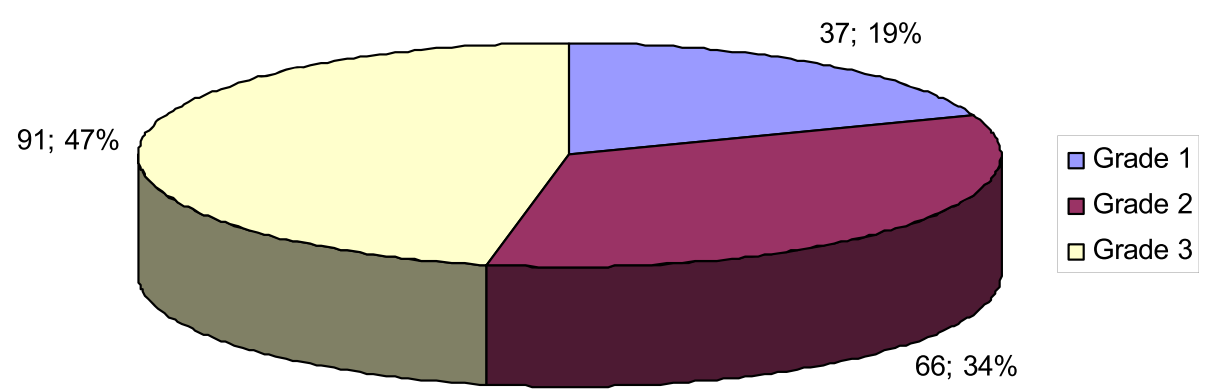

Fig. 1 Flint injury scale

The effects of gender $(p=0.03)$, the type of trauma $(p=$ $0.02)$, the degree of colon injury $(p<0.001)$, the treatment methods $(p<0.001)$, the presence of additional organ injury $(p=0.02)$, the ISS $(p<0.001)$, RTS $(p<0.001)$, and the TRISS $(p<0.001)$ were found to be significant on mortality rates. The types of trauma $(p=0.02)$, the TRISS $(p=0.008)$, the ISS $(p<0.001)$, the RTS $(p=0.03)$, the treatment methods $(p=0.001)$, the TSI $(p<0.001)$ and the degree of colon injury $(p<0.001)$ were observed to have significant effects on morbidity (Table 3 ).

Regression analysis showed that Flint injury degree, TSI and treatment type had no significant effect on mortality. The ISS (OR 1.1; CI $95 \% 1.01-1.2 ; p=0.02$ ), the RTS (OR 0.37 ; CI $95 \% 0.21-0.67 ; p=0.001)$ and the types of trauma (penetrating-blunt distinction) (OR 0.5; CI $95 \%$ $0.01-0.39 ; p=0.004$ ) had significant effects on mortality. While the effects of TSI (OR 5.3; CI $95 \%$ 1.5-18.8; $p=0.01$ ) and Flint injury degree (OR 3.2; CI $95 \%$ $1.47-7.23 ; p=0.004$ ) were found to be significant for morbidity; there were no significant correlation observed between morbidity and the TRISS, RTS, ISS or the types of treatment (Table 4).

\section{Discussion}

It is difficult to determine the incidence of colorectal traumatic injury. In general war series, it has been reported to be as high as $5-10 \%$. Recently, in the Iraq war data that evaluated more than 3400 trauma patients, the incidence of colorectal injury was found to be $5.1 \%$. A recent study of colorectal injuries encountered in Afghanistan and Iraq reveals that $71 \%$ of injuries occurred secondary to penetrating trauma, $23 \%$ were secondary to blast, and $5 \%$ occurred during blunt trauma. In civilian series it is observed to be $1-3 \%$. This rate is lower in blunt trauma

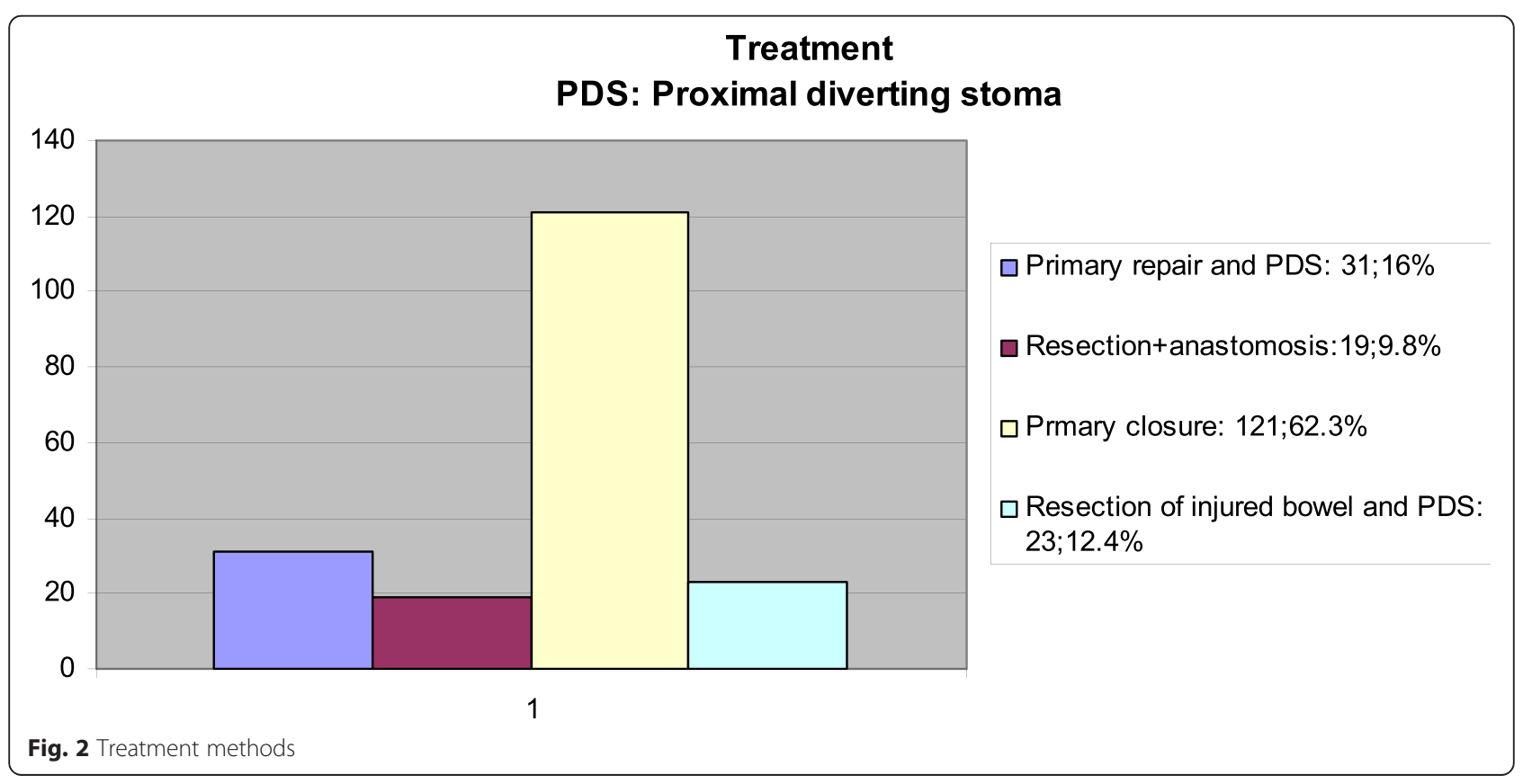




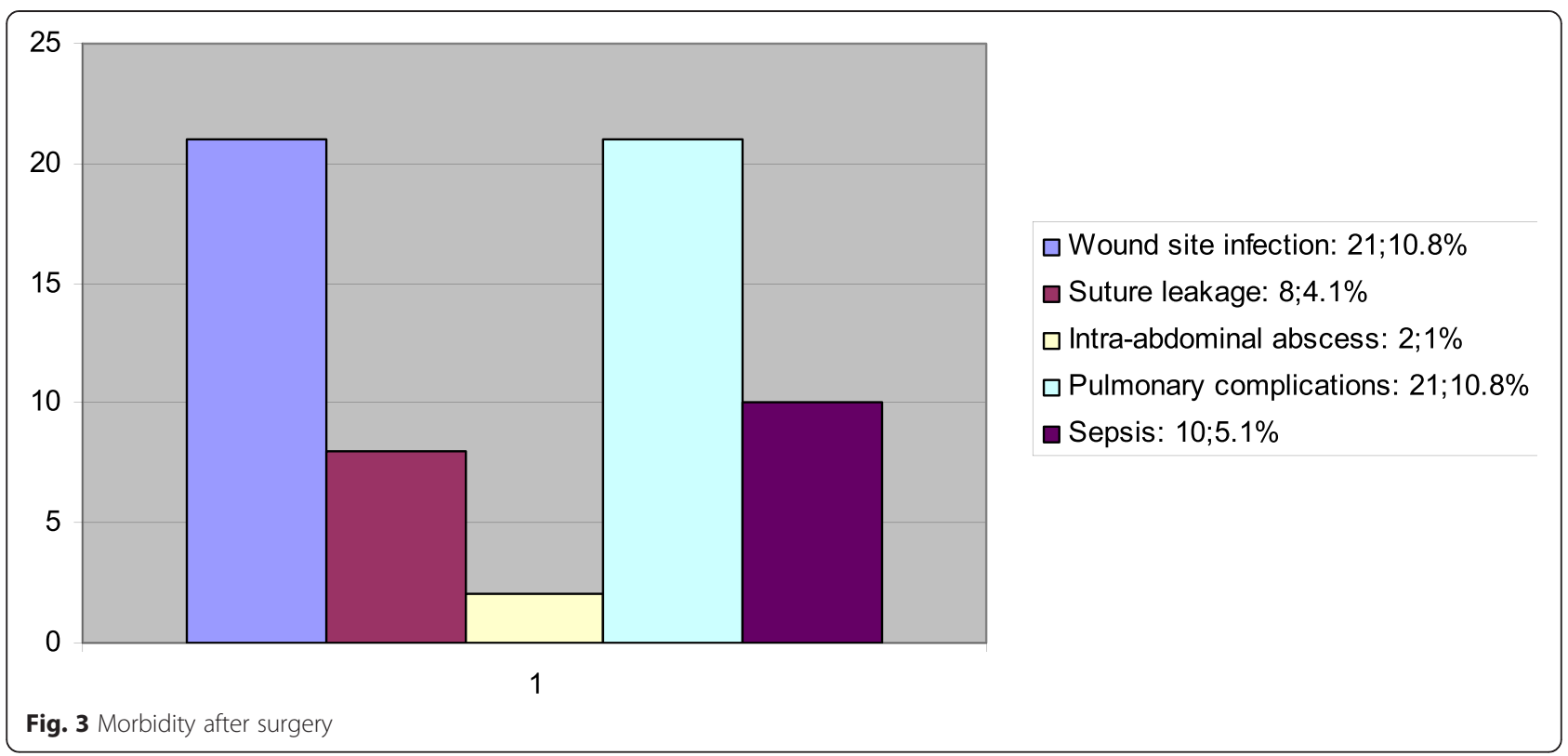

$[4,10-12]$. During the peace time, $80-90 \%$ of colon injuries are non-destructive colon injuries. In contrast, in war time, $72 \%$ of colon injuries are destructive injuries [7]. In our study destructive injuries ratios were $46.9 \%$. These high rates of destructive and penetrating injuries may result from the low intensity war between an armed organisation and government forces in our region between 1985 and 2010, and resulting increase of other types of crimes due to social disorder.

Table 1 The other organs with injuries

\begin{tabular}{lll}
\hline Addition organ wounds & Number & Percent \\
\hline Small bowel & 101 & 52 \\
Stomach & 28 & 14,4 \\
Kidney & 22 & 11,3 \\
Vascular & 18 & 9,2 \\
Diaphragm & 17 & 8,7 \\
Liver & 16 & 8,2 \\
Lung & 14 & 7,2 \\
Spleen & 11 & 5,6 \\
Bladder & 8 & 4,1 \\
Pancreas & 3 & 1,5 \\
Cardiac & 3 & 1,5 \\
Gall bladder & 2 & 1 \\
Ureter & 2 & 1 \\
Urethra & 2 & 1 \\
Oesophagus & 1 & 0,5 \\
Testicle & 1 & 0,5 \\
Multiple small bowel & 41 & 21,1 \\
\hline
\end{tabular}

Table $\mathbf{2}$ Comparison of characteristics of blunt injury group and penetrating injury group

\begin{tabular}{|c|c|c|c|}
\hline & $\mathrm{PIG}(n=179)$ & $\mathrm{BIG}(n=15)$ & $P$ value \\
\hline Age (years), mean $\pm S D$ & $28.9 \pm 12.5$ & $31.2 \pm 11.2$ & 0.3 \\
\hline Gender, males, $n(\%)$ & $159(88.8)$ & $13(86.6)$ & 0.68 \\
\hline \multicolumn{4}{|l|}{ Treatment, $n(\%)$} \\
\hline Primary repair & $132(73.7)$ & $8(53.3)$ & 0.13 \\
\hline Stoma procedure & $47(26.3)$ & $7(46.7)$ & 0.13 \\
\hline \multicolumn{4}{|l|}{ Flint injury scale } \\
\hline Grade 1 and 2 & $96(53.6)$ & $7(46.7)$ & 0.8 \\
\hline Grade 3 & $83(46.4)$ & $8(53.3)$ & 0.8 \\
\hline \multicolumn{4}{|l|}{ TSI, n(\%) } \\
\hline$<8$ hours & $165(92.1)$ & $10(66.6)$ & 0.008 \\
\hline$>8$ hours & $14(7.9)$ & $5(33.4)$ & 0.008 \\
\hline ISS, mean \pm SD & $29.7 \pm 14.2$ & $33.5 \pm 11.8$ & 0.08 \\
\hline $\mathrm{RTS}$, mean $\pm \mathrm{SD}$ & $7.2 \pm 1.3$ & $7 \pm 0.9$ & 0.03 \\
\hline TRISS, mean \pm SD & $85 \pm 26.1$ & $88.2 \pm 12.3$ & 0.07 \\
\hline Hospitalization (days), mean \pm SD & $11.2 \pm 9.3$ & $9.8 \pm 8.1$ & 0.23 \\
\hline Morbidity, $n(\%)$ & $53(29.6)$ & $9(0.6)$ & 0.02 \\
\hline Wound site infection & $18(10.1)$ & $3(20)$ & \\
\hline Suture leakage & $8(4.5)$ & - & \\
\hline Intraabdominal abscess & $2(1.1)$ & - & \\
\hline Pulmonary complications & $16(8.9)$ & $5(33.3)$ & \\
\hline Sepsis & $9(5)$ & $1(6.7)$ & \\
\hline Mortality, n (\%) & 19 (10.6) & $5(33.4)$ & 0.02 \\
\hline
\end{tabular}

PIG penetrating injury group, BIG blunt injury group, TSI, trauma-surgery interval, ISS injury severity score, RTS revised trauma score, TRISS trauma-injury severity score 
Table 3 Factors affecting morbidity and mortality following colorectal injury

\begin{tabular}{|c|c|c|c|c|c|c|}
\hline & \multicolumn{3}{|l|}{ Morbidity } & \multicolumn{3}{|l|}{ Mortality } \\
\hline & Yes $(n=62)$ & No $(n=132)$ & $P$ value & Yes $(n=24)$ & No $(n=170)$ & $P$ value \\
\hline Age, mean $\pm S D$ & $28.3 \pm 11.5$ & $29.5 \pm 12.7$ & 0.54 & $30.5 \pm 14.2$ & $28.9 \pm 12.1$ & 0.57 \\
\hline Gender (male), $n$ (\%) & $52(83.8 \%)$ & 120 (90.9\%) & 0.15 & $18(75 \%)$ & $154(90.5 \%)$ & 0.03 \\
\hline \multicolumn{7}{|l|}{ Treatment, $n(\%)$} \\
\hline Primary repair & $35(56.5 \%)$ & $105(79.5 \%)$ & 0.001 & $8(33.3 \%)$ & $132(77.6 \%)$ & $<0.001$ \\
\hline Stoma procedure & $27(43.5 \%)$ & $27(20.4 \%)$ & & $16(66.7 \%)$ & $38(22.4 \%)$ & \\
\hline \multicolumn{7}{|l|}{ Flint injury scale, $n(\%)$} \\
\hline Grade 1 and 2 & $17(27.4 \%)$ & $86(65.2 \%)$ & $<0.001$ & $3(12.5 \%)$ & $100(58.8 \%)$ & $<0.001$ \\
\hline Grade 3 & $45(72.6 \%)$ & $46(34.8 \%)$ & & $21(87.5 \%)$ & $70(41.2 \%)$ & \\
\hline \multicolumn{7}{|l|}{ TSI, $n(\%)$} \\
\hline$<8$ hours & $47(75.8 \%)$ & $128(97 \%)$ & $<0.001$ & $19(79.2 \%)$ & $156(91.8 \%)$ & 0.07 \\
\hline$>8$ hours & $15(24.2 \%)$ & $4(3 \%)$ & & $5(20.8 \%)$ & $14(8.2 \%)$ & \\
\hline ISS & $35.4 \pm 14.5$ & $27.5 \pm 13.1$ & $<0.001$ & $51.7 \pm 8.6$ & $27 \pm 11.8$ & $<0,001$ \\
\hline RTS & $6.86 \pm 1.6$ & $7.36 \pm 1.1$ & 0.03 & $4.84 \pm 2$ & $7.53 \pm 0.73$ & $<0,001$ \\
\hline TRISS & $77.2 \pm 31$ & $88.9 \pm 21.1$ & 0.008 & $36.6 \pm 28.9$ & $92 \pm 15.4$ & $<0,001$ \\
\hline \multicolumn{7}{|c|}{ Additional organ injuries, $n$ (\%) } \\
\hline None & $11(17.7 \%)$ & $32(24.2 \%)$ & 0.07 & $1(4.2 \%)$ & $42(24.7 \%)$ & 0.02 \\
\hline 1 organ & $28(45.2 \%)$ & $65(49.2 \%)$ & & $11(45.8 \%)$ & $82(48.2 \%)$ & \\
\hline 2 or more organs & $23(37.1 \%)$ & $35(26.5 \%)$ & & $12(50 \%)$ & $46(27.1 \%)$ & \\
\hline Region, $n$ (\%) & & & & & & 0.8 \\
\hline Caecum & $5(8 \%)$ & $7(5.3 \%)$ & 0.36 & 0 & $12(7 \%)$ & \\
\hline Right colon & $8(13 \%)$ & $14(10.6 \%)$ & & $4(16.6 \%)$ & $18(10.6 \%)$ & \\
\hline Transverse colon & $18(29 \%)$ & $50(37.9 \%)$ & 0.36 & $9(37.5 \%)$ & $59(34.7 \%)$ & \\
\hline Left colon & $12(19.4 \%)$ & $15(11.3 \%)$ & & $4(16.6 \%)$ & $23(13.5 \%)$ & \\
\hline Sigmoid colon & $9(14.5 \%)$ & $32(24.2 \%)$ & & $5(20.8 \%)$ & $36(21.2 \%)$ & \\
\hline Intraperitoneal rectum & $3(4.8 \%)$ & $5(3.9 \%)$ & & $1(4.2 \%)$ & $7(4.1 \%)$ & \\
\hline Extraperitonral rectum & $7(11.3 \%)$ & $9(6.8 \%)$ & & $1(4.2 \%)$ & $15(8.9 \%)$ & \\
\hline \multicolumn{7}{|l|}{ Group, $n(\%)$} \\
\hline Penetrating & $53(85.5 \%)$ & $126(95.6 \%)$ & 0.02 & $19(79.2 \%)$ & $160(94.1 \%)$ & 0.02 \\
\hline Blunt & $9(14.5 \%)$ & $6(4.5 \%)$ & & $5(20.8 \%)$ & 10 (5.9\%) & \\
\hline
\end{tabular}

TSI trauma-surgery interval, ISS injury severity score, RTS revised trauma score, TRISS trauma-injury severity score

Table 4 Statistics of morbidity and mortality in multivariate analysis

\begin{tabular}{|c|c|c|c|c|c|c|c|c|}
\hline \multirow{2}{*}{$\begin{array}{l}\text { Factors } \\
\text { Group }\end{array}$} & \multirow{2}{*}{$\begin{array}{l}P \text { value } \\
0.149\end{array}$} & \multirow{2}{*}{$\frac{\mathrm{OR}}{0.367}$} & \multicolumn{2}{|c|}{ Cl \% 95 range } & \multirow{2}{*}{$\begin{array}{l}P \text { value* } \\
0.004\end{array}$} & \multirow{2}{*}{$\frac{O R^{*}}{0.500}$} & \multicolumn{2}{|c|}{ Cl \% 95 range $^{*}$} \\
\hline & & & 0.94 & 1433 & & & 0.006 & 0.390 \\
\hline Flint injury scale & 0.004 & 3.261 & 1.471 & 7.228 & 0.346 & 0.300 & 0.250 & 3.668 \\
\hline Treatment & 0.382 & 0.701 & 0.316 & 1.556 & 0.222 & 0.362 & 0.710 & 1.847 \\
\hline TSI & 0.01 & 5.303 & 1.493 & 18.835 & 0.132 & 4.633 & 0.629 & 34.151 \\
\hline RTS & 0.776 & 0.906 & 0.460 & 1.785 & 0.001 & 0.376 & 0.211 & 0.671 \\
\hline ISS & 0.507 & 1.015 & 0.971 & 1.062 & 0.019 & 1.104 & 1.017 & 1.199 \\
\hline TRISS & 0.834 & 1.005 & 0.960 & 1.052 & & & & \\
\hline
\end{tabular}


In the study by $\mathrm{Ng}$ et al., that evaluated 1367 patients with blunt trauma, they found the incidence of colorectal injury to be $0.1 \%$ [13]. Similarly, Carillo et al. found the incidence of colorectal injury to be $0.5 \%$ following blunt trauma [14]. In a multicenter prospective study conducted with 297 patients in the years after 2000 by Demetriades et al., two-thirds of the destructive injuries requiring resection were treated with primary repair; colon related mortality was found to be significantly lower in the primary repair group $(0 \%$ and $4 \%, p=$ 0.012 ) and no difference was observed in terms of colon related complications ( $22 \%$ and $27 \%, p=0.373$ ) [4]. In the study by Miller et al., while 153 patients (73 \%) without destructive injuries had primary suturing performed, of the 56 patients with destructive injuries, 40 (19\%) had resection and anastomosis and $16(7.6 \%)$ had stomas [15]. In our study, 140 patients (71 \%) had primary repair performed and 54 patients $(29 \%)$ had stomas. Morbidity was found to be significantly higher in the ostomy group than in the primary repair group (primary repair: $25 \%$, ostomy: $50 \%, p<0.001$ ). While $70.4 \%$ of the stoma performed patients had destructive injuries, $37.9 \%$ of the primary repair performed patients had destructive injuries $(p<0.001)$. High morbidity in the stoma group by univariate analysis may be associated with high ratio of destructive injury patients. In civilian injuries, the incidence of anastomotic leakage following primary repair is between 1 and $15 \%$ [16, 17]. In their evaluation of 2964 patients, Curran et al. reported this incidence as being $2.4 \%$ [18]. Demetriades at al. in a multicenter prospective trial involving 19 trauma centers that included 297 patients with destructive colon injuries requiring resection, found that there were no difference between primary repair and stoma in term of anastomotic leakage [4]. Cleary et al., reported hemodynamic instability and shock as risk factors for anastomotic leakage and infective complications [19]. In our study, anastomotic leakage was $4.1 \%$. There was a significant relationship between anastomotic leakage ratio and more than 8 hours of TSI $(p<0.001)$ and the increase in the degree of injury $(p=0.004)$. We detected the anastomotic leakage ratio to be $3.6 \%$ in the primary repair group and $5.6 \%$ in the stoma group $(p<0.05)$. Although we did not reach a clear conclusion as to why more anastomotic leakage was observed in the stoma group, the significantly low levels of RTS observed in the stoma group might suggest that there was more hemodynamic instability in the stoma performed patient group (7.39 vs. 6.69 and $p<0.05)$.

Pinedo, Çöl and Gümüş et al. did not find any significant relationship between age and gender with morbidity in their studies [20-22]. In our study, there was no significant relationship between age and gender with morbidity.
In many studies, the most common organ injury accompanying colon injuries were reported as being small bowel injuries [21-25]. In the studies by Çöl et al., detected at least one accompanying organ injury in $70 \%$ of the patients [21]. In the study by Adesanya et al., where they investigated penetrating colon injuries, the organ injuries most commonly accompanying colon injuries were found to be the small bowel $(73.3 \%)$, the liver $(25 \%)$ and the stomach (23.3\%) [25]. In our study, the ratio of accompanying organ injury was $77.8 \%$ and the most common accompanying organ injured was the small bowel. In literature, although the second most common organ injuries accompanying colorectal injury after the small bowel were reported as being the spleen or liver [23, 25]. In our study, the spleen ranked fifth. We observed that stomach, kidney and vascular injuries more commonly accompanied colorectal injuries than spleen injuries. This difference can be explained by the fact that higher percentage $(92.3 \%)$ of the patients had penetrating injury and $56 \%$ of the colorectal injuries were in the transverse and sigmoid colon. While there was an increase in mortality when colorectal injury was accompanied by two or more organ injuries, $(p=0.021)$, there was no significant increase in observed morbidity $(p=0.07)$. In our study, there was no significant correlation detected between wound localization and mortality or morbidity $(p>0.05)$.

In a study by Singh et al., where they compared the predictive capacity of scoring systems related to trauma; they observed that the RTS and TRISS were better than ISS in predicting the likelihood of survival. Again in the same study: The RTS ranged from 2.746 to 7.8408 . There was a graded increase in mortality with decreasing RTS score. There was a graded increase in mortality with increasing ISS scores [6]. In our study univariate analysis, there were significant relationships observed between ISS increase and both RTS and TRISS decrease with increased morbidity and mortality. While in multivariate analysis there were no relationship between these scoring systems and morbidity. Therewere relationships between ISS, RTS and mortality in multivariate analysis. Increased ISS was associated with increased mortality and increased RTS was associated with decreased mortality. We suggest that this arises from the higher ratios of destructive injuries observed in our patients. The positive effect of a TSI $<8$ hours on morbidity had been known since the study of Stone and Fabian, which was confirmed with later studies $[2,4,22,26]$. In our study, $9.8 \%$ of the patients were taken to surgery after 8 hours and $90.2 \%$ were taken to surgery earlier than 8 hours. In patients taken to surgery after 8 hours, the high morbidity was significant $(p=$ 0.010 and $\mathrm{OR}=5.303 \%$ CI 1.493-18.835).

When the mortalities occurring in the first 24 hours were excluded from the study, the TSI was observed to have significant effect on mortality $(p<0.05)$. 


\section{Conclusion}

Objective criteria are needed for evaluation of trauma patients. Using these scoring systems should be used routinely for follow up and predicting morbidity and mortality. Rapid transfer to the hospital, early diagnosis and treatment of patients with possible traumatic colorectal injury will reduce morbidity and mortality rates. Predicting mortality by using scoring systems and a close follow up of the patients postoperatively may reduce morbidity and mortality rates. Our study shows that there are correlations between trauma scoring indexes and morbidity and mortality. This results imply that there is a need for randomized, prospective controlled studies for adopting these scoring indexes for a better patient treatment and care.

\section{Competing interests}

The authors declare that they have no competing interests.

\section{Authors' contributions}

NA analyzed the results and wrote the manuscript and participated in the study design. VA participated in the study design and assisted in the acquisition of data and provided intellectual contributions to the manuscript draft. IA participated in the study design and assisted in the acquisition of data and provided intellectual contributions to the manuscript draft. US participated in the study design and assisted in the acquisition of data and provided intellectual contributions to the manuscript draft. ŞK participated in the study design and assisted in the acquisition of data and provided intellectual contributions to the manuscript draft. BD participated in the study design and assisted in the acquisition of data and provided intellectual contributions to the manuscript draft. All authors read and approved the final manuscript.

\section{Author details}

${ }^{1}$ Diyarbakır Gazi Yaşargil Education and Research Hospital, Transplantation Center, Diyarbakır, Turkey. 'Department of General Surgery, Diyarbakir Gazi Yaşargil Education and Research Hospital, Diyarbakır, Turkey. ${ }^{3}$ Department of General Surgery, Akdeniz University Hospital, Antalya, Turkey. ${ }^{4}$ Department of Cardiovascular Surgery, Diyarbakır Gazi Yaşargil Education and Research Hospital, Diyarbakır, Turkey. ${ }^{5}$ Department of İnfectious Disease, Diyarbakır Gazi Yaşargil Education and Research Hospital, Diyarbakır, Turkey. ${ }^{6}$ Atatürk State Hospital, Antalya, Turkey.

Received: 5 November 2014 Accepted: 30 April 2015

Published online: 12 May 2015

\section{References}

1. Brady RR, O'Neil S, Berry O, Kerssens JJ, Yalamarthi S, Parks RW. Traumatic injury to the colon and rectum in Scotland: demographics and outcome. Colorectal Dis. 2012;15(1):e 16-22.

2. Govender M, Madiba TE. Current management of large bowel injuries and factors influencing outcome. Injury. 2010;41(1):58-63.

3. JDuBose J. Colonic trauma: indications for diversion vs. repair. Gastrointest Surg. 2009;13(3):403-4.

4. Demetriades D, Murray JA, Chan L, Ordoñez C, Bowley D, Nagy KK, et al. Penetrating colon injuries requiring resection: diversion or primary anastomosis? An AAST prospective multicenter trial. J Trauma. 2001;50:765-75

5. Aydin SA, Bulut M, Ozgüç H, Ercan I, Türkmen N, Eren B, et al. Should the new injury severity score replace the injury severity score in the trauma and injury severity score? Ulus Travma Acil Cerrahi Derg. 2008;14:308-12.

6. Singh J, Gupta G, Garg R, Gupta A. Evaluation of trauma and prediction of outcome using TRISS method. J Emerg Trauma Shock. 2011:4(4):448-9.

7. Sammour T, Kahokehr A, Caldwell S, Hill AG. Venous glucose and arterial lactate as biochemical predictors of mortality in clinically severely injured trauma patients—a comparison with ISS and TRISS. Injury. 2009;40:104-8.
8. Yağmur Y, Güloğlu C, Uğur M, Akkuş Z, Elik Y. Evaluation of patients with multiple injuries: comparison of injury severity score and revised trauma score. Ulus Travma Acil Cerrahi Derg. 1997;3:73-7.

9. Orhon R, Eren ŞH, Karadayı \$̧, Korkmaz I, Coşkun A, Eren M, et al. Comparison of trauma scores for predicting mortality and morbidity on trauma patients. Ulus Travma Acil Cerrahi Derg. 2014;20(4):258-64.

10. Steele SR, Wolcott KE, Mullenix PS, Martin MJ, Sebesta JA, Azarow KS, et al. Colon and rectal injuries during operation Iraqi Freedom: are there any changing trends in management or outcome? Dis Colon Rectum. 2007;50(6):870-7.

11. Johnson EK, Steele SR. Evidence-based management of colorectal trauma. J Gastrointest Surg. 2013;17(9):1712-9.

12. Cho SD, Kiraly LN, Flaherty SF, Herzig DO, Lu KC, Schreiber MA. Management of colonic injuries in the combat theater. Dis Colon Rectum. 2010;53(5):728-34.

13. Ng AK, Simons RK, Torreggiani WC, Ho SG, Kirkpatrick AW, Brown DR. Intraabdominal free fluid without solid organ injury in blunt abdominal trauma. J Trauma. 2002;52(6):1134-40.

14. Carrillo EH, Somberg LB, Ceballos CE, Martini Jr MA, Ginzburg E, Sosa JL, et al. Blunt traumatic injuries to the colon and rectum. J Am Col Surg. 1996;183(6):548-52.

15. Miller PR, Fabian TC, Croce MA, Magnotti LJ, Elizabeth Pritchard F, Minard G, et al. Improving outcomes following penetrating colon wounds: application of a clinical pathway. Ann Surg. 2002;235(6):775-81.

16. Stewart RM, Fabian TC, Croce MA, Pritchard FE, Minard G, Kudsk KA. Is resection with primary anastomosis following destructive colon wounds always safe? Am J Surg. 1994;168(4):316-9.

17. Sharpe JP, Magnotti LJ, Weinberg JA, Shahan CP, Cullinan DR, Marino KA, et al. Applicability of an established management algorithm for destructive colon injuries after abbreviated laparotomy: a 17-year experience. J Am Coll Surg. 2014;218(4):636-41.

18. Curran TJ, Borzotta AP. Complications of primary repair of colon injury: literature review of 2964 cases. Am J Surg. 1999;177(1):42-7.

19. Cleary RK, Pomerantz RA, Lampman RM. Colon and rectal injuries. Dis Colon Rectum. 2006;49(8):1203-22.

20. Pinedo-Onofre JA, Guevara-Torres L, Sanchez-Aquilar JM. Penetrating abdominal trauma. Cir Cir. 2006;74(6):431-42.

21. Col C, Dolapcı M, Yılmaz A. Procedures without colostomy in the surgical emergent treatment of colonic injuries. Ulus Travma Acil Cer Derg. 1997:3:42-7

22. Gümüş M, Kapan M, Önder A, Böyuk A, Girgin S, Taçyıldız I. Factors affecting morbidity in penetrating rectal injuries: a civillian experience. Ulus Travma Acil Cer Derg. 2011;17(5):401-6.

23. Muffoletto JP, Tate JS. Colon trauma: primary repair evolving as the standart of care. J Nat Med Assoc. 1996;88(9):574-8.

24. Musa O, Ghildiyal JP, CPandey M. 6 Year prospective clinical trial of primary repair versus diversion colostomy in colonic injury cases. Indian J Surg. 2010;72(4):308-11.

25. Adesanya AA, Ekanem EE. A ten-year study of penetrating injuries of the colon. Dis Colon Rectum. 2004;47(12):2169-77.

26. Stone HH, Fabian TC. Management of perforating colon trauma: randomization between primary closure and exteriorization. Ann Surg. 1979;190(4):430-5.

\section{Submit your next manuscript to BioMed Central and take full advantage of:}

- Convenient online submission

- Thorough peer review

- No space constraints or color figure charges

- Immediate publication on acceptance

- Inclusion in PubMed, CAS, Scopus and Google Scholar

- Research which is freely available for redistribution 